\title{
¿QUÉ PUEDEN APORTAR LAS NUEVAS TEORÍAS DE LA REFERENCIA AL DEBATE ENTRE HART Y DWORKIN?*
}

\author{
Lorena Ramírez Ludeña \\ Universidad Pompeu Fabra
}

RESUMEN. Tras reconstruir los elementos que considero centrales de las nuevas teorías de la referencia, según las cuales los individuos no tienen que asociar los términos con descripciones que les sean transparentes y que determinen la referencia, en este trabajo sostengo que, aunque generalmente se las asocia con concepciones no positivistas acerca del derecho, resultan también compatibles con el positivismo de corte hartiano y, de hecho, de utilidad en su disputa con DWORKIN por lo que respecta a los desacuerdos jurídicos.

Palabras clave: DwORKIN, positivismo jurídico, nuevas teorías de la referencia, interpretación jurídica, desacuerdos teóricos.

\section{What Can Contribute New Reference Theories to the Debate Between Hart and Dworkin?}

ABSTRACT. After reconstructing what I consider to be the core elements of new theories of reference, according to which individuals do not need to associate words to transparent descriptions that determine their reference, in this paper I defend that, although they are generally associated with non-positivist conceptions of law, new theories of reference are also compatible with hartian positivism and they are, in fact, useful in the dispute with DWORKIN regarding legal disagreements.

Keywords: DwORKIN, legal positivism, new theories of reference, legal interpretation, theoretical disagreements.

\footnotetext{
* Fecha de recepción: 29 de abril de 2015. Fecha de aceptación: 23 de diciembre de 2015.
} 


\section{INTRODUCCIÓN}

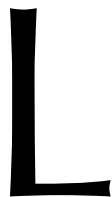

as nuevas teorías de la referencia no han sido objeto de gran atención en el ámbito jurídico. Estas teorías defienden que los individuos no tienen que asociar los términos con descripciones que les sean transparentes y que determinen la referencia. Los prejuicios asociados con ellas, así como una bien asentada concepción convencionalista acerca del derecho, han dificultado que su incidencia haya sido mayor ${ }^{1}$. Entre los teóricos del derecho, con frecuencia no están del todo claros cuáles son los rasgos centrales de estas teorías. Además, se las suele asociar a posiciones fuertemente esencialistas y por ello se las entiende como incompatibles con la naturaleza institucional del derecho. Finalmente, se las tiende a vincular con teorías no positivistas acerca del derecho. Ello es explicable en la medida en que los (pocos) autores que han sostenido las nuevas teorías de la referencia en el derecho han adherido a teorías abiertamente no positivistas, defendiendo versiones robustas de los principales elementos de las nuevas teorías, especialmente por lo que respecta a sus compromisos metafísicos. Y, en el marco de sus teorías acerca del derecho, autores como BrinK, MOORE o STAVROPOUlOS han añadido a tales consideraciones otras muchas asunciones que pueden ser desvinculadas de las tesis centrales de las nuevas teorías la referencia ${ }^{2}$.

La asociación de estas teorías con posiciones no positivistas se ha puesto también de manifiesto en el debate en torno a Ronald DwORKIN. Así, algunos han sostenido que este autor debe comprometerse con las nuevas teorías de la referencia si quiere dar sentido a su noción de desacuerdos teóricos. De este modo, se ha señalado que la crítica de DWORKIN a las concepciones semánticas ${ }^{3}$ viene dada por su rechazo de los conceptos criteriológicos que él atribuye al positivismo, pero que sí podría y debería adoptar las nuevas teorías de la referencia ${ }^{4}$.

Tras presentar los principales rasgos de las nuevas teorías de la referencia, en este trabajo trataré de mostrar cómo los argumentos ofrecidos por el propio DWORKIN ${ }^{5}$ para diferenciar los conceptos interpretativos, que él suscribe para ámbitos como el derecho, de los conceptos de clase natural no son concluyentes. Por ello, conforme a sus afirmaciones, no puede sostenerse de manera tajante que las nuevas teorías son incompatibles con su posición. Sin embargo, el propósito central del trabajo no es hacer una exégesis de la posición de DwORKIN, ni mostrar la compatibilidad de su posición con las nuevas teorías de la referencia, sino sostener una tesis mucho más controvertida: que son compatibles con el positivismo jurídico de corte hartiano. En este sentido, en la última parte del trabajo defenderé la compatibilidad de dichas teorías con las principales tesis positivistas, al entender que su relevancia depende de cómo se desarrollen contingentemente nuestras prácticas de identificación e interpretación. Además, argumentaré que este constituye un modo adecuado de reconstruir solo algunos términos del derecho. Ello se opone a otra asunción habitual en el ámbito jurídico:

\footnotetext{
1 Acerca del carácter convencional del derecho, vid. MARMOR, 2009, y VILAJOSANA, 2010.

2 Vid. BrinK, 1988; MOORE, 1985, y StaVRopoulos, 1996.

3 DwORKIN, 1986: 31-37.

4 Vid., por ejemplo, Rodríguez-Blanco, 2001.

5 DwORKIN, 2006: 19 y ss.; 2011: 158 y ss.
} 
si una concepción semántica (convencionalista, interpretativa, etc.) es adecuada, lo es para todos los términos del derecho.

\section{RECONSTRUCCIÓN DE LOS ELEMENTOS CENTRALES DE LAS NUEVAS TEORÍAS DE LA REFERENCIA}

Entre los partidarios de las nuevas teorías de la referencia encontramos que los diversos autores enfatizan diferentes aspectos, por lo que es comprensible que no resulte claro cuáles son sus rasgos característicos. Con el propósito de defender su incidencia en la interpretación jurídica, expondré los elementos que considero fundamentales. Esto me permitirá mostrar en el próximo apartado que los argumentos de DwORKIN contra la relevancia de los conceptos de clase natural en el derecho no son concluyentes. Como veremos, frecuentemente se asocia a las nuevas teorías de la referencia con rasgos discutibles que en realidad son marginales. Por otro lado, en ocasiones son sus propios partidarios quienes se han comprometido con rasgos que no me parecen centrales y que las tornan problemáticas. Por ello, ofreceré una reconstrucción de las nuevas teorías de la referencia, más que una descripción de las diversas opiniones de los autores que han desarrollado esta corriente. Así, pretendo enfatizar algunos rasgos de los usualmente señalados y descartar otros, de modo que las nuevas teorías de la referencia se conviertan en una alternativa plausible a las concepciones tradicionales ${ }^{6}$.

Si tenemos en cuenta los trabajos de los partidarios de las nuevas teorías de la referencia, la tesis que comparten es fundamentalmente negativa ${ }^{7}$. Según la concepción tradicional, los individuos son capaces de referirse a los objetos porque cuentan con información acerca de ellos, que determina a qué se refieren. En cambio, los defensores de las nuevas teorías de la referencia han señalado que los sujetos son capaces de referirse a los objetos incluso cuando carecen de esa información. Dicho de otro modo, niegan lo que el modelo tradicional afirma: que los sujetos asocian los términos con ciertas descripciones que determinan aquello a lo que se refieren. Asimismo, conforme con el modelo tradicional, los individuos son competentes en el uso del lenguaje en la medida en que vinculan los términos con ciertas descripciones que determinan la referencia. Los partidarios de las nuevas teorías, en cambio, no requieren de descripciones que identifiquen el objeto para considerar al sujeto competente y, en todo caso, aquella información que sí consideran relevante a efectos de la competencia no determina aquello a lo que nos referimos ${ }^{8}$.

\footnotetext{
6 Para una reconstrucción más extendida, vid. RAMírEZ LuDEÑA, 2014b.

7 Tomaré como autores principales a efectos de reconstruir los aspectos básicos de las nuevas teorías de la referencia a DONNELLAN (1970), KRIPKE (1980) y PUTNAM (1975). Los dos primeros se centraron fundamentalmente en los nombres propios, y PUTNAM en los términos de clase natural.

8 Los argumentos de los partidarios de las nuevas teorías de la referencia para alcanzar estas conclusiones enfatizan, a partir de ejemplos, que frecuentemente los hablantes competentes en el uso de los términos cuentan con información escasa y equivocada de los objetos a los que, no obstante, son capaces de referirse. Por esta razón, las descripciones no pueden determinar la referencia. Acerca de estas cuestiones, vid. DONNELLAN, 1970: 347 y ss. Se considera que FrEGE (1998a y 1998b) y RuSSELL (1905 y 1910-1911) son los dos autores más representativos de la concepción tradicional. No obstante, esta es una cuestión que puede fácilmente controvertirse si tomamos en cuenta sus escritos. Por otro lado, frente a posiciones que se centran en los sujetos individualmente considerados, hay versiones de la concepción tradicional que asumen una posición socializada
} 
Más allá de este núcleo básico de acuerdo, los posicionamientos de los partidarios de las nuevas teorías de la referencia difieren en gran medida. Así, algunos autores han elaborado concepciones acerca de cómo se determina la concreta referencia de un término, distinguiendo entre su fijación y su transmisión. KRIPKE, de modo paradigmático, ha destacado la relevancia de consideraciones histórico-causales. De acuerdo con su posición, nuestro uso depende de usos anteriores que, en última instancia, se remontan a un acto de bautismo inicial en que el nombre queda vinculado con el objeto. Además, tener la intención de usar el término con la misma referencia que aquel de quien se lo adquirió resulta fundamental. Pensemos en un nombre propio como «Aristóteles». Soy capaz de referirme a Aristóteles puesto que he aprendido a usar el término de otro sujeto, que a su vez lo aprendió de otro sujeto, lo que en última instancia se remonta a individuos que estuvieron en contacto directo con Aristóteles. Pero además, debo tener la intención de referirme a ese mismo individuo, lo que no ocurriría si quisiera ponerle el nombre «Aristóteles» a mi perro?.

También se ha destacado, con respecto a nuestro uso de determinados términos, la contribución del mundo al significado y la referencia. En este sentido, imaginemos a dos personas molecularmente idénticas, Oscar 1 y Oscar 2, que habitan planetas idénticos, la Tierra y la Tierra Gemela (respectivamente), con una excepción: la sustancia llamada «agua» en la Tierra Gemela no tiene la composición $\mathrm{H}_{2} \mathrm{O}$, sino XYZ. Como en lo restante los planetas son idénticos, Oscar 1 y Oscar 2 asocian con el término «agua» las mismas descripciones (líquido transparente, insípido, etcétera). Sin embargo, en el caso de Oscar 1 «agua» refiere a $\mathrm{H}_{2} \mathrm{O}$ y en el de Oscar 2 a XYZ. Entonces, aunque no haya nada en los estados mentales de Oscar 1 y Oscar 2, ninguna descripción que puedan especificar, que seleccione $\mathrm{H}_{2} \mathrm{O}$ en lugar de $\mathrm{XYZ}$, parece que «agua» dicho por Oscar 1 es $\mathrm{H}_{2} \mathrm{O}$ y es en cambio XYZ dicho por Oscar 2. Según Putnam, estos experimentos mentales dejan constancia de que las diferencias en los entornos suponen diferencias en las respectivas referencias de los términos, desempeñando así un papel decisivo a la hora de especificar el significado y la referencia en cada uno de los $\operatorname{casos}^{10}$.

Precisamente por entender que los elementos anteriores son fundamentales, se recurre frecuentemente a las denominaciones «teoría causal de la referencia»o «teorías de la referencia directa» para hablar de estas posiciones, pero creo que ello puede conducir a importantes equívocos.

\footnotetext{
y se centran en cúmulos de descripciones que se asocian con los términos a nivel de toda la comunidad. En este sentido, SEARLE (1958) sostiene que el referente es el objeto que satisface un número suficiente (aunque impreciso) de información descriptiva conectada socialmente con el nombre. En todo caso, aquí no me interesa exponer la posición de determinados autores, sino adoptar como punto de partida la concepción a la que se oponen las nuevas teorías de la referencia, concepción que además resulta intuitiva con carácter general puesto que proporciona una sencilla explicación de qué conexión existe entre nuestros términos y los objetos a los que nos referimos, y que puede dar cuenta de cómo aprendemos y enseñamos a usar los términos: mediante descripciones.

9 Sobre estas cuestiones, vid. la segunda conferencia de «Naming and Necessity» en KRIPKE, 1980.

10 Putnam, 1975: 223 y ss. Un partidario del modelo tradicional podría también entender que el modo en que es el mundo tiene un impacto en nuestro uso de los términos. Sin embargo, en tales casos debería además reconocer que ha habido un cambio en el significado y la referencia, lo que sería claramente rechazado por los defensores de las nuevas teorías de la referencia. Por ejemplo, de acuerdo con el modelo tradicional se podría admitir que el descubrimiento de la composición química del agua tiene un impacto en el significado del término «agua», pero se asumiría al mismo tiempo que se ha producido entonces un cambio en el significado del término, fruto de la indagación empírica y de la teorización.
} 
Con respecto a la relación causal, considero que es suficiente exigir que en la comunidad se haya consolidado un determinado uso en relación con el objeto, sin que sea necesario un acto formal de bautismo en el que se produzcan inicialmente ciertos vínculos causales. Y, si bien la existencia de un vínculo con otros miembros de la comunidad permite explicar cómo es que somos capaces de referirnos a objetos distantes en el tiempo y en el espacio, requerir que haya una relación de causalidad es excesivo. Lo relevante es ser parte de la cadena histórica que nos remonta al referente, con la intención de usar el nombre para referirnos a lo mismo que aquel del que lo adquirimos, prescindiendo de analizar el fenómeno de la transmisión de la referencia a partir de las cadenas causales de comunicación ${ }^{11}$.

En lo que hace a la referencia directa a los objetos, generalmente se ha señalado que los partidarios de las nuevas teorías de la referencia defienden que los nombres propios y los términos de clase natural se diferencian de las descripciones puesto que son designadores rígidos cuya contribución a las condiciones de verdad de los enunciados en que aparecen es el objeto al que refieren directamente. Pero no resulta entonces claro si el aspecto determinante de las nuevas teorías de la referencia es o bien la designación rígida, que apunta a que los términos refieren al mismo objeto en todo mundo posible, o bien el hecho de que los términos contribuyen con el objeto a las condiciones de verdad de las oraciones en las que aparecen, o algún otro modo de entender la referencia directa. Dado que los partidarios del modelo tradicional también pueden defender que hay nombres y descripciones rígidas ${ }^{12}$, y que estos contribuyen con el objeto a las condiciones de verdad de los enunciados de que forman parte ${ }^{13}$, no puede afirmarse que lo característico de las nuevas teorías de la referencia sean esos dos elementos. En cuanto a la referencia directa, ya hemos visto cuál es la tesis (negativa básica) de quienes defienden las nuevas teorías. No obstante, ellos no niegan que ciertas descripciones (entre otros elementos) puedan ser relevantes en la fijación y transmisión de la referencia, ni a efectos de ser competente en el uso de los términos ${ }^{14}$. Entonces, el argumento central, de acuerdo con lo que aquí se sostiene, es la referencia directa entendida como el rechazo de la exigencia de que medien descripciones identificadoras de los objetos, y no qué tipo de contribución hacen a las condiciones de verdad o la designación rígida. Pero resulta del todo natural que alguien que sostenga la referencia directa de algunos términos entienda que la contribución de esos términos a las condiciones de verdad de las oraciones es el propio objeto y, además, si reflexiona sobre otras situaciones posibles a la KRIPKE, afirme que son designadores rígidos.

Otros autores han puesto el énfasis en la relevancia de los expertos en el uso de los términos. Es el caso de PUTNAM, quien entiende que la división del trabajo lingüístico se basa en la división del trabajo no-lingüístico, y la presupone. En este sentido, necesitamos, por ejemplo, poder distinguir el oro genuino de cosas que solo se le parecen

${ }^{11}$ Además, los partidarios del modelo tradicional también podrían considerar relevante la existencia de ciertos vínculos causales entre los diversos sujetos, y entre los sujetos y los objetos, por lo que difícilmente puedan ser considerados característicos de las nuevas teorías de la referencia. Sobre las confusiones a que puede conducir el considerar crucial el elemento causal, vid. RAMíREZ LUDEÑA, 2014a.

12 Es el caso de la descripción «el sucesor del número ocho». Acerca de la desvinculación entre referencia directa y rigidez, vid. MARTí, 2003.

13 Sobre la diferencia entre referencia directa y contribución a las condiciones de verdad, vid. MARTí, 1995.

${ }_{14}$ Para un análisis más detallado de estas cuestiones, vid. RAmíREZ LudEÑA, 2014b. 
externamente, pero no se precisa que todos aquellos para los que la distinción es importante puedan distinguirlos. Y ello supone también una división del trabajo lingüístico: todo aquel para quien el oro es importante tiene que adquirir la palabra, pero no el método para reconocer si algo es o no oro. Puede fiarse de una subclase de hablantes y es la comunidad lingüística considerada como un cuerpo colectivo la que cuenta con la información necesaria para que cada uno de los hablantes que la componen emplee los términos, pese a que estos no puedan precisar descripciones identificadoras ${ }^{15}$. Sin embargo, vincular las nuevas teorías de la referencia con la deferencia a los expertos puede también conducir a equívocos. Y ello no solo porque la existencia de deferencia a los expertos podría ser suscrita por los partidarios de la concepción tradicional ${ }^{16}$, sino además porque los defensores de las nuevas teorías de la referencia no sostienen que todos los términos dependan de los expertos.

Finalmente, uno de los elementos más controvertidos de la posición de los partidarios de las nuevas teorías de la referencia es su esencialismo. Expondré primero, brevemente, por qué creo que se produce el prejuicio antiesencialista por parte de algunos filósofos analíticos. A continuación, trataré de precisar en qué sentido considero que las nuevas teorías de la referencia asumen posiciones esencialistas. Sostendré entonces que no tienen que comprometerse con una forma implausible de esencialismo.

Con frecuencia, especialmente durante la primera mitad del siglo XX, los filósofos analíticos han asumido que la única necesidad admisible es la conceptual ${ }^{17}$. Así, se ha entendido que una proposición es contingente si su verdad o falsedad depende de cómo es el mundo, y necesaria si depende de nuestros conceptos y la relación entre ellos. Las proposiciones contingentes pueden conocerse a posteriori, y las necesarias a priori. La propuesta de los partidarios de las nuevas teorías de la referencia se enfrenta radicalmente a la posición clásica. De hecho, KRIPKE y sus seguidores han rechazado la vinculación entre lo necesario y lo a priori y han sostenido que hay verdades necesarias a posteriori y verdades contingentes a priori.

El modo de entender la necesidad por parte de algunos filósofos analíticos ha tenido además un fuerte impacto por lo que respecta a la forma de reflexionar acerca de otros mundos posibles y las esencias. Desde su punto de vista, la necesidad, ligada a nuestras decisiones conceptuales arbitrarias, determina la reflexión acerca de otras situaciones posibles. De esta manera, si hemos optado porque «agua» signifique sustancia incolora, inodora e insípida que quita la sed, no existe mundo posible en que el agua no sea precisamente esa sustancia, puesto que en eso consiste ser agua. Y ello determina también la cuestión de las esencias (en aquellos casos en que admiten el discurso acerca de ellas): es esencial al agua ser una sustancia incolora, inodora e insípida que quita la sed, precisamente por nuestra decisión lingüística. El resto de características, no integradas en nuestra definición, son accesorias ${ }^{18}$.

15 Putnam, 1975: 227 y ss.

16 Con una matización: si bien para los partidarios de las nuevas teorías de la referencia la deferencia en los expertos no es constitutiva, en el sentido de que ellos también podrían equivocarse, esto no es así en caso de que un defensor del modelo tradicional incorpore el elemento de la deferencia. Para este último, lo que el experto sostenga constituirá el significado y determinará la referencia del término.

17 Sobre estas cuestiones, vid. PÉrez OTERO, 2006: 21 y ss.

18 Ibid., 87 y ss. 
En cambio, asumir que no requerimos de descripciones que determinan la referencia de nuestras palabras permite la recuperación del debate esencialista. Así, puesto que la cuestión de las descripciones relevantes no queda fijada de antemano, sino que depende de la indagación empírica y de la teorización, tiene sentido plantearnos qué podría haber ocurrido en otras situaciones, lo que da cabida a la reflexión sobre las propiedades esenciales tomando en cuenta lo que habría acontecido en otros mundos posibles ${ }^{19}$.

Ello explica entonces la revitalización del debate acerca del esencialismo, al evitar el prejuicio derivado de la asunción del modelo tradicional. No obstante, por sí misma, la concepción semántica de los partidarios de las nuevas teorías de la referencia no puede fundamentar una cuestión metafísica como es la de si existen o no las esencias. Lo que sí sostienen es que la práctica tiene asunciones esencialistas y que tiene sentido que así sea porque nuestro lenguaje no pone trabas para ello ${ }^{20}$.

Pero, si se entiende que nos referimos a los objetos conforme a lo señalado por los partidarios de las nuevas teorías de la referencia, ¿cómo cabe entender que ello ocurre específicamente en el caso de determinados términos de clase? ¿Qué tipo de compromiso esencialista asumimos al emplear esos términos? Veámoslo a partir del ejemplo del oro. Introducimos un término (en este caso, «oro») para referirnos a una sustancia como el oro, y lo hacemos en relación con instancias de la clase sin la necesidad de que medien descripciones que determinen la referencia. $\mathrm{Y}$ al plantearnos situaciones contrafácticas hablamos precisamente de esa sustancia, y no de objetos que satisfacen ciertas descripciones. La determinación del rasgo fundamental que determina la aplicación correcta del término «oro» requiere de investigación empírica y de teorización, orientadas a concretar cuál es la propiedad que condiciona la pertenencia a la clase. Y, en este caso, confiamos en los expertos para que identifiquen cuál es esa propiedad, que determina si algo es o no oro en cualquier situación posible: si descubrimos un lugar distante a la Tierra donde hay algo superficialmente parecido al oro pero con un número atómico distinto, no diríamos que allí tienen oro. Si el oro es la sustancia cuyo número atómico es 79 , nada cuenta como oro si no tiene el número atómico $79^{21}$.

19 Cabe añadir que los partidarios de las nuevas teorías de la referencia no tienen que adoptar una determinada concepción metafísicamente comprometida acerca de los mundos posibles, sino que pueden entender que los mundos posibles representan meramente posibilidades, modos en que las cosas podrían ser. En cambio, algunos de los defensores de la posición tradicional parecen adoptar lo que se denomina una «concepción telescópica» acerca de los mundos posibles, es decir, entienden que se trata de un mundo similar al nuestro que puede observarse mediante el uso de un telescopio. En tal planteamiento, algo será agua si es cualitativamente idéntico a nuestra agua. La vinculación entre la visión telescópica de los mundos posibles, que requiere de criterios de identidad entre mundos, y la concepción tradicional acerca de la relación entre nombres propios y descripciones que he descrito es solo contingente. Se trata de una mera generalización, útil sin embargo para comprender por qué tradicionalmente se ha rechazado que podamos reflexionar acerca de las propiedades de los objetos. Defendiendo la existencia de una vinculación entre la visión telescópica y la concepción tradicional similar a la expuesta, ibid., 125 y ss.

${ }_{20} \mathrm{Y}$, si bien es cierto que los propios partidarios de las nuevas teorías de la referencia, KRIPKE de modo paradigmático, han defendido también argumentos de tipo metafísico, esos argumentos pueden distinguirse, como así hago en este trabajo, de los argumentos centrales relativos a su posición semántica.

21 Dejo aquí de lado determinadas elementos controvertidos, como es si nos referimos a entidades abstractas o a los diversos objetos con los que nos relacionamos, o la distinción entre esencias y propiedades esenciales, así como los diversos modos de entender qué son las propiedades esenciales. Sobre estas cuestiones, vid. RAmíREZ LuDEÑa, 2014b. 
En todo caso, hablar de propiedades esenciales no nos compromete con un único modo de vincular nuestros términos con el mundo, o con la inmutabilidad de los objetos a los que hacemos referencia. De hecho, las cosas podrían haber sido de otro modo en múltiples sentidos que expondré a continuación, lo que cobrará especial importancia en los próximos apartados de este trabajo.

Por un lado, nosotros podríamos ser de otro modo. Podríamos ser individuos con capacidades para observar cosas que ahora no observamos, en cuyo caso podríamos haber fijado la referencia de los términos de clase a partir de otras instancias distintas. De hecho, si imaginamos que somos capaces de apreciar con facilidad el número de neutrones de los objetos, probablemente hubiéramos clasificado inicialmente los objetos de manera distinta a como lo hacemos actualmente. Aun así, ser $\mathrm{H}_{2} \mathrm{O}$ podría continuar siendo lo relevante si es lo que nos parece que tiene mayor capacidad explicativa y predictiva. Además, nuestros intereses y otras consideraciones contingentes tienen una relevancia crucial: ser $\mathrm{H}_{2} \mathrm{O}$ es determinante por el auge que ha tenido un determinado sector científico en un momento dado.

Además, nuestro lenguaje podría ser distinto, es decir, podríamos haber llamado a las cosas de otro modo. No obstante, es importante advertir que cuando describimos una situación contrafáctica usamos nuestro idioma con nuestros significados y nuestras referencias, aun cuando sea parte de la descripción de esa situación que hablamos otro idioma, o que hemos etiquetado las cosas de un modo distinto. Así, puedo afirmar que Aristóteles podría no haberse llamado «Aristóteles» de manera no problemática ${ }^{22}$. Asimismo, cuando describimos lo que podría acontecer en la Tierra Gemela, podemos afirmar que emplean el mismo término para algo distinto. En tal caso, dado nuestro uso del término «agua» y de cómo es de hecho nuestro mundo, nada es agua si no es $\mathrm{H}_{2} \mathrm{O}$, incluso aunque se le llame del mismo modo.

Nada impide tampoco que cambiemos nuestro uso de las palabras y que empleemos términos que antes usábamos con respecto a un objeto o clase para algo distinto. En estos casos, la referencia del término habría sido modificada, y emplearíamos el mismo término para algo distinto. Esto puede pasar de manera deliberada o no, como ocurrió en el caso Madagascar. Se dice que «Madagascar» refería inicialmente a una parte del continente africano y no a la isla, pero que acabó refiriendo a la isla como consecuencia de una confusión de los exploradores. Este podría ser un caso problemático para las nuevas teorías de la referencia porque hay una relación causal entre los diversos hablantes, que trataron de preservar la referencia de aquellos de los que aprendieron el nombre, pero hay además un error sistemático. ¿Por qué no refieren nuestros usos actuales del término «Madagascar» a la parte del continente a la que hacía referencia inicialmente el término, en lugar de referir a la isla ${ }^{23}$ ? Autores como DEviTT han introducido la noción de anclaje múltiple para dar respuesta a este tipo de situaciones, lo que nos permite hablar en estos casos de un cambio en la referencia cuando se consolida un nuevo uso del mismo término para un objeto distinto. Según DeviTT, lo relevante es que se crea una red en relación con el objeto y el uso del término por parte de los hablantes, red en la que puede haber modificaciones si se producen nuevos vínculos

\footnotetext{
22 KRIPKE, 1980: 79.

23 La crítica fue inicialmente planteada por EvANS, 1973.
} 
causales. Los defensores de las nuevas teorías de la referencia podrían dar cuenta, por tanto, de los cambios de referencia. Ello puede suponer, evidentemente, que haya un lapso de tiempo en que determinados usos refieran al continente, y otros a la isla, o en que la referencia esté indeterminada ${ }^{24}$.

Como ocurrió en el caso del jade, el mundo podría ser de otro modo, en el sentido de que podríamos haber descubierto que las diferentes instancias no tenían una misma estructura profunda. Así, no me comprometeré con que solo hay un modo en que las cosas pueden ser. Esto es, aquello que llamamos «agua» en la Tierra podría haber resultado ser tanto $\mathrm{H}_{2} \mathrm{O}$ como XYZ. A efectos de identificar las propiedades esenciales es fundamental tener en cuenta cómo se ha desarrollado la historia del uso del término y cómo es de hecho el mundo, porque eso determina qué elementos van a ser importantes y cuáles van a ser nuestros compromisos con respecto a otras situaciones posibles. En la Tierra podría haber habido $\mathrm{H}_{2} \mathrm{O}$ y XYZ (dos variedades, como de hecho pasó con el jade), y podríamos haber reconocido entonces dos clases de agua. Sin embargo, dado cómo usamos el término y qué es de hecho el agua, nada cuenta como agua si no es $\mathrm{H}_{2} \mathrm{O}$. Ello es precisamente lo que plasman los experimentos mentales de la Tierra Gemela. Y, si hubiésemos descubierto diferencias microscópicas importantes en los ejemplares y otras diferencias de apariencia, probablemente hubiéramos concluido que los objetos en cuestión no constituían una clase. Nuestras reacciones en estos supuestos pueden depender de múltiples factores, por ejemplo, de si tenemos otros términos que empleamos para cosas similares.

Por otro lado, nosotros podríamos descubrir que de hecho el mundo es de un modo distinto de como creíamos que era. Es decir, podemos hacer descubrimientos que nos lleven a rechazar como parte de una clase cosas que creíamos incluidas. Como las propiedades esenciales pueden trascendernos, es evidente que los partidarios de las nuevas teorías de la referencia aceptan esta posibilidad. Se trata solo de dificultades epistémicas para determinar las extensiones correctas de nuestros términos.

Existe otro sentido en que parece intuitivo pensar que las cosas podrían haber sido de otro modo, y que también se vincula con consideraciones de tipo epistémico. Así, en cierto modo nos parece que el vínculo entre agua y $\mathrm{H}_{2} \mathrm{O}$ es contingente, que las cosas podrían ser de otro modo, porque nos imaginamos en una situación epistémica similar a la que nos hallamos frente al agua, y en la que acabamos descubriendo que eso que cae del cielo, que está en los ríos, que nos quita la sed, es XYZ. Pero solo tenemos, diría KRIPKE, la ilusión de que el vínculo es contingente: dado que el agua es $\mathrm{H}_{2} \mathrm{O}$, nada es agua si no es $\mathrm{H}_{2} \mathrm{O}^{25}$.

Tampoco va en detrimento de las nuevas teorías de la referencia el hecho de que el mundo pueda cambiar: podrían alterarse las propiedades de las cosas e incluso desaparecer los diferentes objetos. Pero si todas las partículas de $\mathrm{H}_{2} \mathrm{O}$ mutaran a XYZ, ¿diríamos que ya no hay agua o que el agua es ahora XYZ? Aunque se trata de una cuestión profundamente controvertida, puede sostenerse que los partidarios de las nuevas teorías no tienen que comprometerse con una respuesta al respecto porque su

\footnotetext{
24 Sobre estas cuestiones, vid. DevitT, 1981, y DevitT y Sterelny, 1999: 76.

25 Vid. KRIPKE, 1980: 102 y ss.
} 
argumento central es que, dada la historia del uso del término y cómo son de hecho las cosas, el agua es $\mathrm{H}_{2} \mathrm{O}$. Qué pasaría en esas otras circunstancias (si se produce el cambio de $\mathrm{H}_{2} \mathrm{O}$ a XYZ) parece depender de muchos y complejos factores ${ }^{26}$.

Entonces, en un sentido relevante la referencia de nuestros términos depende de cómo se ha desarrollado la historia del uso del término, y de nuestros descubrimientos y teorización. Conferir esa incidencia a nuestras prácticas tendrá, como veremos en el último apartado, una importancia fundamental a efectos de poder sostener la compatibilidad de las nuevas teorías de la referencia con concepciones positivistas acerca del derecho, puesto que estas últimas enfatizan la relevancia de nuestras prácticas de identificación e interpretación contingentes.

Un aspecto a destacar de las nuevas teorías de la referencia es que tomarlas en consideración permite dar cuenta de los desacuerdos. Si las descripciones que los individuos asocian con los términos no determinan la referencia, estos pueden estar discutiendo acerca de lo mismo pese a tener concepciones diferentes del objeto al que no obstante refieren. Ello permite además dar cuenta de los progresivos cambios en las concepciones (entre diferentes sujetos, o con respecto a un mismo sujeto con el transcurso del tiempo). Como veremos, estos aspectos adquirirán una relevancia fundamental en el debate entre HART y DwOrKIN.

\section{DWORKIN Y LAS NUEVAS TEORÍAS DE LA REFERENCIA}

En su análisis del fenómeno jurídico, DwORKIN destaca el carácter interpretativo de la práctica. Esto es, entiende que los juristas discuten habitualmente acerca de lo que el derecho requiere y defienden sus posiciones ofreciendo razones ${ }^{27}$. Concretamente, de acuerdo con DwORKIN la argumentación jurídica tiene un carácter creativo y constructivo. Por un lado, y del mismo modo que ocurre, por ejemplo, en el caso del arte, el derecho supone un ejercicio de interpretación creativa, en el cual se pretende interpretar algo creado por los individuos como una entidad distinta de ellos. En este sentido, determinar en qué consiste la práctica y qué requiere es algo diferente de determinar qué creen sus participantes. El razonamiento jurídico es además un ejercicio de interpretación constructiva, lo que significa que el derecho consiste en la mejor justificación de nuestras prácticas consideradas como un todo. La interpretación constructiva supone adscribir un propósito a un objeto o práctica para hacerlo el mejor ejemplo posible del tipo o género al que pertenece. Conforme a lo señalado por DwORKIN, atribuimos un propósito a la práctica a la luz del cual se determinan sus exigencias. Sin embargo, no todo tiene cabida, puesto que la historia o la manera en que la práctica u objeto se ha desarrollado restringe las interpretaciones disponi-

26 Admitir la posibilidad de que se produzcan esos cambios exige entender de un determinado modo las propiedades esenciales. Habría que asumir que los partidarios de las nuevas teorías de la referencia se comprometen con la existencia de rasgos esenciales que condicionan la pertenencia a la clase, pero no conque la clase cuente con esa propiedad necesariamente, ni que los objetos pertenezcan necesariamente a la clase en cuestión. De este modo, podrían mantener su posición al mismo tiempo que sostienen que el agua podría pasar a ser $\mathrm{XYZ}$, o que determinados elementos dejaran de ser agua.

27 Según Dworkin (1986: 13), cada actor entiende que lo que el derecho establece depende de la verdad de ciertas proposiciones que solo tienen sentido en el marco de la práctica. 
bles $^{28}$. En este sentido, el mejor propósito es el que muestra la práctica bajo su mejor luz, equilibrando el respeto por la historia de la práctica y su justificación. En particular, el propósito del derecho es, según DwORKIN, el ejercicio justificado de la coerción estatal, tomando en consideración los derechos y responsabilidades de los individuos que derivan de las decisiones políticas del pasado ${ }^{29}$.

Los desacuerdos que, de acuerdo con DwORKIN, dejan constancia del carácter argumentativo del derecho no se limitan a disputas generales acerca de si la moral constituye o no un criterio de validez jurídica, o al rol desempeñado por los principios en el razonamiento jurídico, sino que se ponen generalmente de manifiesto cuando se discute lo que establece el derecho en un sistema jurídico particular invocando diferentes modos de entender las disposiciones.

DwORKIN critica el positivismo de corte hartiano por no dar cuenta de la naturaleza interpretativa del derecho y no poder dar cabida a los desacuerdos jurídicos. Pero, ¿por qué el positivismo no puede ofrecer una reconstrucción adecuada de tales supuestos? Conforme a lo señalado por DwORKIN, el problema es que para los positivistas el derecho es una cuestión de hechos históricos en relación, por ejemplo, a lo que el legislador o los tribunales han decidido en el pasado ${ }^{30}$. Es decir, la verdad de las proposiciones jurídicas - de las afirmaciones con respecto a lo que un sistema jurídico establece para un determinado supuesto- depende de ciertos hechos históricos que constituyen los fundamentos (grounds) del derecho ${ }^{31}$. Esos hechos, y no otros, son relevantes, de acuerdo con el positivismo, porque existe entre los officials del sistema jurídico en cuestión la convención de considerarlos los fundamentos del derecho. Entonces, según DwORKIN, el positivismo podría dar cuenta de los desacuerdos empíricos, sobre si se han producido ciertos hechos en el pasado, pero no podría reconocer controversias acerca de qué elementos son jurídicamente relevantes. Así, no pueden ofrecer una caracterización adecuada de los llamados «desacuerdos teóricos», sobre los fundamentos del derecho, y deben entender que en realidad se trata de desacuerdos acerca de cómo debe ser el derecho ${ }^{32}$.

De acuerdo con DwORKIN, en ocasiones se niega la posibilidad de que existan desacuerdos teóricos porque se suscriben teorías semánticas acerca del derecho. Las teorías semánticas sostienen que el significado de las palabras depende de criterios compartidos. En el caso del derecho, esto supone asumir que los juristas usan los mismos

28 DwORKIN, 1986: 45 y ss. DwORKIN (1986: 66 y ss.) distingue tres estadios, que no suelen diferenciarse claramente en la práctica: el pre-interpretativo, el interpretativo y el post-interpretativo. Acerca de las etapas de la interpretación constructiva, vid. IGLESIAS, 1999: 142-145.

29 DwORKIN, 1986: 93. Aunque no me detendré en ello, DwORKIN (1986: 176 y ss.) defiende, tras analizar el convencionalismo y el pragmatismo, el derecho como integridad. Vid. IGLESIAS, 1999: 148 y ss.

30 DWORKIN, 1986: 7 y ss.

31 En mi reconstrucción, emplearé el término «fundamentos» en lugar de, por ejemplo, «criterios de identificación» o «fuentes», precisamente porque, como trataré de mostrar, los desacuerdos destacados por DWORKIN versan sobre cuestiones diversas: en ocasiones, sobre los criterios, otras acerca de las fuentes, a veces sobre cuestiones interpretativas, etcétera.

32 Los desacuerdos teóricos suponen diferentes reconstrucciones sobre lo que determina la verdad de las proposiciones jurídicas. Los desacuerdos empíricos, en cambio, asumen un acuerdo sobre los elementos determinantes, pero cuestionan si estos se han instanciado. En opinión de STAVROPOULOS (1996: 125), los desacuerdos teóricos o sustantivos son acerca de si algo es $\mathrm{X}$, lo que desemboca en diferentes perspectivas respecto de cuándo algo es $\mathrm{X}$. 
criterios al decidir si las proposiciones jurídicas son verdaderas o falsas. Así, conforme a la reconstrucción dworkiniana del positivismo, el propio significado de la palabra «derecho» hace que el derecho dependa de criterios compartidos y que el acuerdo en los fundamentos del derecho sea determinante ${ }^{33}$. Este es el conocido argumento del aguijón semántico, que es introducido para explicar por qué los positivistas requieren que los criterios que empleamos para determinar cuándo las proposiciones jurídicas son verdaderas se establezcan por consenso ${ }^{34}$. Volveré sobre la cuestión del aguijón semántico en el próximo apartado de este trabajo.

En trabajos posteriores, DwORKIN varía la argumentación anterior, distinguiendo diferentes tipos de conceptos (criteriológicos, de clase natural, e interpretativos) y atribuyendo al positivismo la tesis según la cual el concepto de derecho es criteriológico. Es decir, el énfasis no es ahora que el positivismo asume una concepción semántica sino que, de entre las posibilidades conceptuales disponibles, opta por la criteriológica, lo que no le permite dar cuenta de los desacuerdos jurídicos. A efectos de diferenciar esos conceptos, DwORKIN se plantea qué supuestos y prácticas deben ser compartidos por los individuos para que podamos afirmar que comparten lo que denomina «el concepto doctrinal de derecho», relativo a las concretas exigencias de los sistemas jurídicos particulares ${ }^{35}$.

DWORKIN señala que, en el caso de los conceptos criteriológicos, los individuos los comparten solo cuando se ponen de acuerdo en una definición que establece los criterios para la correcta aplicación del término en cuestión. Desarrollar una teoría de este tipo de concepto significa proponer una definición más precisa para algún propósito concreto, pero sería un error sostener que la definición más precisa captura mejor que el resto la esencia del concepto. En cuanto a los conceptos de clase natural, los individuos comparten conceptos cuyas instancias tienen una estructura física o biológica, aunque no estén de acuerdo en la naturaleza esencial de los ejemplos o en los criterios que utilizan para identificar tales ejemplos. En estos casos, la ciencia puede afirmar que ha descubierto una esencia auténtica, lo que no tendría sentido en el caso de los conceptos criteriológicos. Finalmente, los conceptos interpretativos nos animan a reflexionar y cuestionar aquello que exige alguna práctica que hemos construido. Los individuos comparten estos conceptos pese a los desacuerdos profundos sobre los criterios y las instancias. Y, apunta DwORKIN, si los otros tipos de conceptos se ven inmersos en prácticas interpretativas generalmente terminan operando de modo interpretativo.

De acuerdo con DwORKIN, la práctica lingüística convergente determina la correcta aplicación tanto de los conceptos criteriológicos como de los naturales, aunque de modo distinto. Quienes comparten un concepto criteriológico pueden desacordar y equivocarse sobre si los criterios de aplicación se dan en un caso concreto. Quienes comparten un concepto de clase natural pueden equivocarse de un modo más fundamental: pueden equivocarse sobre la naturaleza esencial de las propiedades de los

33 DwORKIN, 1986: 31-37.

34 Ibid., 33. Aunque DwORKIN señala en su trabajo que el positivismo ha sido picado por el aguijón semántico, generalmente se utiliza la expresión para apuntar a la propia crítica de DwORKIN.

35 DwORKIN, 2006: 19 y ss. Sobre los distintos tipos de conceptos y las diferencias entre ellos, vid. GREEN, 2003. 
conceptos y también sobre instancias. No obstante, identificar esos errores presupone que subyace una práctica convergente que vincula el concepto a alguna clase natural en concreto. En el caso de los conceptos interpretativos, estos también requieren que las personas compartan una práctica, en el sentido de que deben coincidir en tratar el concepto como interpretativo, pero esto no quiere decir que tengan que converger en la aplicación del concepto. Una teoría útil de un concepto interpretativo no puede limitarse a informar de los criterios que la gente usa para identificar instancias ni a indagar sobre la estructura profunda de lo que comúnmente se acuerda que son instancias, sino que debe ser ella misma una interpretación, que muy probablemente será controvertida, de la práctica en la que figura ese concepto.

Especificando las cuestiones anteriores, DwORKIN sostiene años después que compartimos un concepto interpretativo cuando nuestro comportamiento colectivo al usar ese concepto se explica de un mejor modo si consideramos que su correcto uso depende de la mejor justificación del rol que desempeña para nosotros ${ }^{36}$. En el caso de los conceptos criteriológicos, compartimos el concepto solo en la medida en que usamos los mismos criterios para identificar las instancias. Entonces, los desacuerdos no tienen sentido porque serían disputas verbales, aunque DwORKIN reconoce que los conceptos criteriológicos son vagos y, aunque los individuos acuerden sobre los criterios para su aplicación, pueden desacordar sobre casos que son marginales. Finalmente, las clases naturales tienen una identidad fija en la naturaleza, una esencia, y estos conceptos son compartidos cuando se los usa para referir a la misma clase natural, aunque no usen los mismos criterios para identificar las instancias. En ambos casos (conceptos criteriológicos y de clase natural) los individuos no comparten los conceptos a no ser que acepten que hay un test decisivo, un procedimiento de decisión, para decidir cuándo aplicar el concepto (salvo en casos que se consideren marginales). En cambio, en el caso de los interpretativos, los compartimos manifestando una comprensión de que su aplicación correcta se fija por la mejor interpretación de las prácticas en que figuran. Además, añade DwORKIN, en el caso de los conceptos de clase natural hay acuerdo en los paradigmas, pero no es así en los interpretativos.

Me centraré ahora específicamente en el contraste entre los conceptos de clase natural y los interpretativos. De acuerdo con lo que acabo de exponer, DwORKIN presenta una versión diferente de los conceptos de clase natural a la expuesta al comienzo de este trabajo en relación con las nuevas teorías de la referencia. De hecho, entendidos de ese modo esos conceptos son cuestionables y difícilmente pueden ser considerados en el ámbito de la interpretación jurídica. Sin embargo, y atendiendo a lo señalado en el apartado anterior, considero que estas teorías pueden ser entendidas de un modo más plausible, puesto que no se comprometen con la existencia de una esencia inmutable, confiriendo un rol central al modo en que se desarrollan nuestras prácticas. En este sentido, argumentaré que las apreciaciones de DwORKIN contra los conceptos de clase natural se basan en la asunción de una versión cuestionable de ellos y, siguiendo a STAVROPOULOS ${ }^{37}$, que lo que suscribe con respecto a los conceptos interpretativos no

\footnotetext{
36 DWORKIN, 2011: 158 y ss.

37 Stavropoulos, 1996: 160 y ss.
} 
se halla significativamente alejado de lo que he señalado acerca de las nuevas teorías de la referencia al comienzo de este trabajo.

Hemos visto que DwORKIN señala que los desacuerdos no requieren de la existencia de criterios comunes, sino que es suficiente con que los individuos compartan una caracterización abstracta de la práctica que tratan de interpretar y algunos paradigmas, aunque estos no son infalibles ${ }^{38}$. Pues bien, según STAVROPOULOS, ambos elementos resultan acordes con las principales tesis de los partidarios de las nuevas teorías de la referencia. Así, de acuerdo con STAVROPOULOS, tanto en la reconstrucción de DwORKIN como en la de los defensores de las nuevas teorías de la referencia, los términos pretenden seleccionar conceptos, sea cual sea su contenido. Su determinación depende de consideraciones sustantivas y está limitada por los paradigmas y por las caracterizaciones abstractas de la práctica de aplicación relevante que, no obstante, pueden variar con el tiempo.

La compatibilidad entre DwORKIN y los partidarios de las nuevas teorías de la referencia, e incluso la necesidad de que DwORKIN asuma dichas teorías para dar sentido a su posición, ha sido abordada por diversos autores, aunque de un modo distinto al que aquí se seguirá. Frecuentemente, se ha señalado que los argumentos de DWORKIN contra las concepciones arquimedianas son insuficientes, y que él mismo asume una posición externa a las propias prácticas en su análisis ${ }^{39}$. Asimismo, se ha enfatizado que no sostener una concepción realista metafísica más robusta lo conduce a no poder dar sentido a la noción de desacuerdos teóricos, central en su teoría, y a caer inexorablemente del lado convencionalista ${ }^{40}$.

DwORKIN rechaza que haya restricciones externas a los sujetos que interpretan, aunque asume que puede haber restricciones objetivas a los juicios. De acuerdo con su posición, solo contamos con el discurso interno, en el marco del cual no hay diferencias entre afirmar que las montañas existen o que realmente existen. Defender la objetividad externa como criterio de corrección presupone que tenemos acceso al mundo, lo que según DwORKIN no tiene sentido porque no podemos salir de nuestros esquemas conceptuales. $\mathrm{Y}$, en todo caso, la consecuencia de rechazar que podamos acceder a la realidad directamente no es que las creencias constituyen el mundo y por tanto que todo vale, sino que hay interpretaciones objetivamente mejores que otras ${ }^{41}$.

Entonces, dado que suele entenderse que las nuevas teorías de la referencia asumen la distinción entre nuestras creencias y lo real, resulta frecuente defender la incompatibilidad entre las nuevas teorías de la referencia y DwORKIN. No obstante, se ha señalado que DwORKIN debe asumir compromisos metafísicos más fuertes, cercanos a los de los partidarios de las nuevas teorías de la referencia, si no quiere encontrarse con los mismos problemas que él denuncia con respecto a los desacuerdos, puesto que

38 DwORKIN, 1986: 31 y ss. DwORKIN reitera que un concepto como el de derecho no requiere de acuerdo subyacente o convergencia en los criterios ni en las instancias de uso en 2006: 244 y ss.

39 DwORKIN llama «arquimedianas» a aquellas concepciones que pretenden llevar a cabo su análisis desde el exterior de la práctica que constituye su objeto de estudio. Acerca de los problemas de la concepción arquimediana de DWORKIN, vid. LEITER, 2001.

40 En este sentido, vid. MoOre, 1987: 247 y ss., Moreso, 1997: 205, y 1999: 303 y ss., Raz, 2001, y RODRÍGUEZ-BLANCO, 2001.

41 DWORKIN, 1986, 1996 y 2011. 
de no hacerlo lo determinante sería en todo caso las creencias de los individuos que discuten.

En contraste con lo anterior, en este trabajo he rechazado que, conforme a los partidarios de las nuevas teorías de la referencia, haya solo un modo correcto de clasificar el mundo, y he enfatizado la relevancia de la historia del uso del término y de nuestros intereses. En muchos sentidos relevantes, las cosas podrían haber sido de otro modo, sin la necesidad de asumir compromisos metafísicos específicos, sino meramente semánticos ${ }^{42}$. Los partidarios de las nuevas teorías de la referencia reconstruyen el modo en el que usamos determinados términos, sin que tengamos que suscribir que los objetos a los que nos referimos realmente existen y pueden ser conocidos con independencia de nuestros esquemas conceptuales. Pero aquí no intentaré mostrar ni la necesidad de que DwORKIN asuma las nuevas teorías de la referencia, ni la compatibilidad de estas con toda su obra, lo que requeriría de un análisis más exhaustivo. Me limitaré en cambio a analizar los argumentos presentados por el propio DwORKIN para contrastar su posición con la de los partidarios de las nuevas teorías de la referencia, a partir de lo que señala sobre los conceptos de clase natural. Si, como defenderé, sus argumentos no son definitivos y puede entenderse que son compatibles con su posición, su noción de desacuerdos está a salvo. Ello parece especialmente claro si tomamos en cuenta que las nuevas teorías de la referencia surgieron, precisamente, para dar sentido a desacuerdos como los señalados por DWORKIN, y difícilmente puede controvertirse su carácter explicativo con respecto a ellos. Además, su concepción resultará más adecuada en la medida en que no requerirá de la introducción de un tipo de concepto específico (los conceptos interpretativos), sino meramente de la consideración de las nuevas teorías de la referencia, que gozan de una amplia aceptación con respecto a numerosos términos en el ámbito de la filosofía del lenguaje.

Hemos visto que DwORKIN concede un lugar principal en su reconstrucción al concepto doctrinal de derecho, que se ocupa de la pregunta relativa a qué prevé un sistema jurídico específico acerca de una cuestión determinada ${ }^{43}$. Según DwORKIN, los individuos desarrollan una actitud interpretativa con respecto a muchas de sus prácticas, entre las que se encuentra el derecho, lo que significa que entienden que la práctica en cuestión tiene un valor y que sus exigencias no se agotan en criterios compartidos, sino que dependen de argumentos que tratan de mostrar la práctica en su mejor luz.

42 Asumiendo una versión robusta de las nuevas teorías de la referencia, IGLESIAS (1999: 133) defiende que la posición de DWORKIN se distingue de la de las nuevas teorías puesto que DwORKIN sostiene que la referencia es un objeto o estado de cosas interpretativo, el producto de la mejor teoría acerca de cómo es el mundo, y no un hecho bruto. De este modo, IGLESIAS considera que los partidarios de las nuevas teorías de la referencia están comprometidos con la existencia de hechos brutos, y al mismo tiempo ignora la relevancia de la teorización. Contra dichas asunciones, vid. el segundo apartado de este trabajo. Es importante advertir que, al tratarse de consideraciones de tipo semántico, las nuevas teorías de la referencia podrían tener cabida incluso si fuera el caso de que la realidad es construida en un sentido relevante por nuestras creencias. El punto central es la dirección de ajuste (de nosotros al mundo), así como las asunciones de los sujetos al referirse a los objetos (aunque nuestros intereses y otras consideraciones importan, empleamos los términos de modo que no todo vale).

43 Menos trascendencia tiene en cambio el concepto sociológico, en virtud del cual usamos el término «derecho» para designar un tipo concreto de estructura social de carácter institucional. Aunque muchos autores han estudiado este concepto, según DWORKIN no existe una naturaleza esencial del derecho, y es suficiente en este ámbito con un concepto rudimentario. DwORKIN (2006: 14 y ss.) hace referencia además al concepto taxonómico, acerca del tipo de estándares que forman parte del derecho, y el aspiracional, sobre el ideal de la legalidad. 
Para que ello sea posible, los individuos deben compartir un lenguaje, entender el mundo de modo similar, y tener intereses y convicciones suficientemente parecidas. En términos wittgensteinianos, DWORKIN sostiene que los individuos que argumentan en el marco de las prácticas en que se ha desarrollado una actitud interpretativa comparten una forma de vida ${ }^{44}$.

DWORKIN niega que haya, en prácticas como la cortesía o el derecho, rasgos definitorios compartidos por las diferentes instancias, y cuya negación supondría que el individuo se está autocontradiciendo. Como he señalado, sí comparten, de acuerdo con su reconstrucción, una caracterización abstracta de la práctica y ciertos paradigmas. Es evidente que las prácticas van sufriendo cambios, y que consideremos o no que estas han variado depende de muchos factores. Incluso, que el aspecto central, el concepto a partir del cual se desarrollan las diversas concepciones, cambie, no determina que nos hallemos ante una práctica distinta, sino que se trata de elementos de las prácticas que son también interpretativos ${ }^{45}$. Además, DwORKIN destaca el papel de los paradigmas, que son ejemplos de los que debe dar cuenta cualquier interpretación plausible. Su incidencia se plasma en el hecho de que argumentar en contra de una interpretación consistirá a menudo en mostrar que no reconstruye adecuadamente un paradigma. Aun así, los paradigmas también pueden ser desafiados, siendo esta también una cuestión interpretativa ${ }^{46}$.

De acuerdo con DwORKIN, los conceptos de clase natural y los interpretativos comparten las siguientes propiedades: son reales, puesto que su existencia y sus rasgos no dependen de la invención, creencia o decisión de nadie; y tienen una estructura profunda que explica el resto de sus características. La diferencia entre ambos, señala DWORKIN, es que la estructura profunda de las clases naturales es física y la de los valores políticos es normativa. Podemos entender que ambas empresas son conceptuales, aunque la tarea con los valores es normativa y comprometida ${ }^{47}$. Así, señala DwORKIN, «[N]o podemos de forma sensata mantener que el análisis filosófico de un valor es conceptual, neutral y no comprometido. Pero sí podemos defender de forma razonable que es normativo, comprometido y conceptual» ${ }^{48}$. Además, en el caso del derecho, en que nos hallamos ante conceptos con una dimensión institucional, asumir que hay conceptos de clase natural resultaría problemático porque, tras recoger los diferentes casos en que hemos hecho referencia, por ejemplo, a la democracia, no contamos con ningún mecanismo para determinar cuáles son sus rasgos esenciales. En palabras de DWORKIN, «todavía necesitaríamos una explicación de qué es lo que hace que un rasgo de un diseño social o político sea esencial para su carácter de democracia y que otro rasgo sea solo contingente» ${ }^{49}$.

Vimos que en escritos posteriores DwORKIN ha retomado la cuestión, aunque con algunas variantes ${ }^{50}$. Según DWORKIN, tanto con respecto a los conceptos criteriológicos

44 DwORKIN, 1986: 45 y ss.

${ }^{45}$ Ibid., 69 y ss.

46 Acerca de estos dos aspectos, DwORKIN, 2011: 160 y ss.

47 DwORKIN, 2006: 173 y 174.

48 Ibid., 174.

49 Ibid., 171.

50 DWORKIN, 2011: 157 y ss. 
como a los de clase natural hay un test decisivo para decidir cuándo aplicar el concepto. El desacuerdo genuino sobre la aplicación se termina entonces cuando acordamos en los hechos pertinentes. Además, DwORKIN precisa que el hecho de que un concepto sea de uno u otro tipo es en sí mismo una cuestión interpretativa. En relación con lo anterior, sostiene que los conceptos pueden variar y un concepto de clase natural pasar a ser interpretativo si, por ejemplo, los científicos empiezan a dudar sobre si el ADN es determinante a efectos de considerar que un animal es un tigre. $\mathrm{Y}$ añade que los términos morales no se ajustan a la reconstrucción de las clases naturales porque estas últimas requieren acuerdo sobre los objetos que caen bajo el concepto.

Entonces, los argumentos centrales que, según el propio DwORKIN, lo diferencian de las nuevas teorías de la referencia, son los siguientes: a) Los conceptos de clase natural, a diferencia de los interpretativos, requieren de una práctica convergente que determine su correcta aplicación; en el caso de los conceptos interpretativos, los individuos deben simplemente coincidir en tratar el concepto como interpretativo; en cambio, tanto con respecto a los conceptos criteriológicos como a los de clase natural hay un test definitivo para decidir cuándo aplicar el concepto, por lo que el desacuerdo genuino sobre la aplicación se termina cuando acordamos en los hechos pertinentes. Y añade que los términos morales no se ajustan a la reconstrucción de las clases naturales porque estas requieren acuerdo sobre los objetos que caen bajo el concepto. b) Las nuevas teorías de la referencia no tendrían aplicación en el derecho porque no contamos con ningún mecanismo para determinar cuáles son sus rasgos esenciales: como he señalado anteriormente, «todavía necesitaríamos una explicación de qué es lo que hace que un rasgo de un diseño social o político sea esencial para su carácter de democracia y que otro rasgo sea solo contingente». c) La estructura profunda de las clases naturales es física y la de los valores políticos es normativa.

Contra lo señalado por DwORKIN cabe destacar, en primer lugar, que los conceptos de clase natural no requieren de un mayor grado de consenso que los conceptos interpretativos: como señalé en el primer apartado, no se requiere acuerdo ni en los objetos que caen bajo el ámbito de aplicación del término, ni acerca del test que determina las aplicaciones correctas. Y, como en el caso del jade, podríamos descubrir que en realidad agrupábamos diversas variedades con propiedades esenciales diversas, o que ni siquiera tiene sentido hablar de propiedades esenciales. Lo que sí se requiere es que, de la misma forma que los conceptos interpretativos, los individuos traten los términos de un determinado modo. Con respecto a la distinta naturaleza esencial de dichos conceptos, y las dificultades señaladas por DwORKIN para considerar los conceptos de clase natural en el derecho, resulta fundamental atender a los argumentos esgrimidos por STAVROPOULOS con la finalidad de establecer un paralelismo entre ambos tipos de conceptos. Las diferencias entre ambos, aunque existentes, no socavarían el potencial explicativo de las nuevas teorías de la referencia, ya que aportan elementos para una articulación más clara de la posición de DWORKIN.

STAVROPOULOS ha sostenido que los conceptos interpretativos son evaluativos y profundos ${ }^{51}$. Son evaluativos, en tanto que nombran valores y su aplicación correcta depende de cuál es el valor, lo que a su vez depende de una teoría acerca del valor que

51 Stavropoulos, 1996: 160 y ss. 
justifique por qué los ejemplos sirven o violan el valor en cuestión, y cómo el valor se vincula con otros. Y son profundos puesto que su aplicación no depende de lo que creamos sino de lo que de hecho sea esencial. Lo esencial no depende de la reflexión $a$ priori sobre el concepto, sino de cuál es la propiedad que explica, en algunos casos, y en otros justifica, las propiedades superficiales de la extensión del término, que sirven a quienes lo emplean para identificar los objetos a los que el concepto se aplica. Ello permite dar cuenta de la posibilidad de error colectivo. Que un concepto tenga o no tal complejidad depende de la propia práctica, pero determinar si es así puede requerir de investigación filosófica, lo que incluye servirse de experimentos mentales. En el caso de los conceptos de clase natural, consideramos que nombran una clase y que su correcta aplicación depende de su naturaleza. La aplicación correcta del concepto dependerá entonces de la mejor teoría sobre la naturaleza de la clase, que explicará rasgos más superficiales y con respecto a la cual cabe error colectivo. De manera similar, aplicamos el término «derecho» tomando como guía ciertas propiedades superficiales. Ciertos valores políticos justifican que el derecho tenga tales propiedades. La diferencia estriba, de acuerdo con STAVROPOULOS, en que, si bien en el caso del agua identificar el rasgo esencial requiere de investigación empírica, en el derecho tendremos que indagar sobre verdades morales necesarias. En este caso, la relación es justificatoria puesto que, a diferencia de los rasgos superficiales del agua, que forman parte de relaciones causales, en el derecho las propiedades superficiales figuran en relaciones normativas. Por ejemplo, aceptamos que la historia institucional de nuestro sistema jurídico genera obligaciones. Tratamos ciertos hechos (por ejemplo, que el Parlamento ha promulgado una nueva ley tributaria) como base para justificar un deber (debo pagar un impuesto), y parece entonces plausible considerar que hay una propiedad profunda de esos hechos que fundamenta su poder normativo.

Así, tomando en cuenta lo señalado por STAVROPOULOS y lo expuesto en el apartado anterior, la posición interpretativa de DWORKIN no parece incompatible con las asunciones de los partidarios de las nuevas teorías de la referencia o, cuanto menos, sus argumentos no son concluyentes. La cuestión es entonces si tomar en consideración las nuevas teorías de la referencia en el derecho requiere de la asunción de la posición de DWORKIN o de otras concepciones no positivistas. Abordaré esa cuestión en el próximo apartado.

\section{LAS NUEVAS TEORÍAS DE LA REFERENCIA Y EL POSITIVISMO DE CORTE HARTIANO}

Ya he señalado que la compatibilidad de DwORKIN con las nuevas teorías de la referencia, e incluso la necesidad de su asunción, son tesis que han sido defendidas con anterioridad, aunque de modos diferentes al que aquí he seguido. En este apartado intentaré sostener una tesis mucho más controvertida y original: trataré de mostrar que la consideración de las nuevas teorías de la referencia en el ámbito jurídico no requiere comprometerse con una concepción interpretativa como la de DWORKIN, o con una concepción no-positivista con carácter general. Para ello, diferenciaré las discusiones relativas al concepto de derecho, de las discusiones sobre los criterios de validez jurídica y su interpretación. Asimismo, sostendré que el positivismo no asume que el dere- 
cho opere de acuerdo con un esquema criteriológico, y defenderé que las tesis positivistas básicas son compatibles con entender que las nuevas teorías de la referencia son relevantes para reconstruir la interpretación de determinados términos en el derecho.

Como hemos visto, en un primer momento DwORKIN destaca que el positivismo no puede ofrecer una caracterización adecuada de los desacuerdos porque defiende una teoría semántica conforme a la cual los individuos comparten criterios para la aplicación del término «derecho», o, lo que considera lo mismo, criterios para decidir cuándo una proposición jurídica es verdadera. Esto supone que los sujetos coinciden, si son competentes en el uso del término, en cuáles son los fundamentos del derecho. Cuestionarlos carecería de sentido puesto que conllevaría cuestionar los propios criterios de aplicación del término. Entonces, si el propio significado de la palabra «derecho» hace que el derecho dependa de criterios compartidos, el positivismo estaría comprometido con asumir que las discusiones sobre los fundamentos del derecho constituyen disputas meramente verbales. Las controversias en este ámbito carecerían de sentido porque los sujetos estarían empleando el mismo término con distintos significados, sin que exista por tanto un desacuerdo genuino ${ }^{52}$.

Si atendemos a los trabajos de HART, la crítica de DwORKIN genera cierta perplejidad: HART no pretende proporcionar una definición de «derecho», sino un análisis del concepto de derecho $\mathrm{o}^{53}$, y manifiesta expresamente su rechazo de semánticas que vinculan los términos con condiciones necesarias y suficientes ${ }^{54}$. Y, aunque sostuvo que en la base de todo sistema jurídico existe una regla de reconocimiento que especifica los criterios para la identificación del derecho, aclaró de manera expresa que no es parte del significado del término «derecho» que tal regla esté presente en todos los sistemas ${ }^{55}$.

La crítica de DwORKIN puede ser cuestionada a partir, fundamentalmente, de dos grupos de argumentos: $a$ ) en su reconstrucción, DwORKIN asocia el modelo positivista bartiano con un modelo semántico criteriológico, pero no hay elementos en la obra del propio HART que nos conduzcan a tal conclusión y, lo que es más importante, hay modelos alternativos más plausibles que el que DwORKIN atribuye al positivismo, y compatibles con el mismo; $b$ ) con independencia de que se sostenga o no el modelo criteriológico, puede cuestionarse la vinculación entre la posición semántica —en sentido estricto, la posición metasemántica ${ }^{56}$ - con respecto al término «derecho» y los criterios para determinar el valor de verdad de las proposiciones jurídicas. Precisamen-

52 La cuestión no es solo que en las disputas los términos deben emplearse con el mismo significado para que estas tengan sentido, sino que además, si las condiciones de aplicación determinan el objeto de controversia, los sujetos estarían discutiendo acerca de cosas distintas. DwORKIN (1986: 37 y ss.) considera que el positivismo se halla en una encrucijada: o sostiene que los desacuerdos recaen sobre casos marginales de aplicación del término, en cuyo caso deberían comprometerse con que carecen de relevancia, o bien que recaen sobre aspectos centrales, y entonces las controversias son solo aparentes porque los sujetos emplean el mismo término con distintos significados.

53 HART, 1994: 81. En este mismo sentido, vid. SHAPIRO, 2011: capítulo 1.

54 HART, 1994: 15. En realidad, sorprendentemente DwORKIN no afirma que el positivismo busque proporcionar una definición del término, sino que es mejor reconstruirlo como una teoría acerca del término «derecho», puesto que es lo que más sentido da a su posición.

55 HART, 1994: 246. Sobre estas cuestiones, vid. ENDICOTT, 2001: 39 y ss.

56 Esto es, el debate con relación a si el positivismo se adhiere o no el modelo criteriológico es un debate metasemántico, acerca de cómo se determina el contenido semántico de los términos y expresiones, que se halla en un nivel distinto de las posiciones específicas con respecto a cuál es el significado del término «derecho». 
te por ello, puede haber desacuerdo acerca de una de las cuestiones sin que lo haya en relación con la otra. Ambas cuestiones son evidentemente muy problemáticas ${ }^{57}$.

Consideremos, en cambio, que los positivistas tratan de capturar los aspectos centrales de la práctica jurídica y que generalmente lo hacen sirviéndose del análisis del concepto de derecho. Bajo una lectura más plausible de la crítica de DwORKIN, así como más acorde a sus escritos ulteriores, esta denunciaría que los positivistas entienden que los sujetos comparten el concepto que ellos tratan de dilucidar, y que compartir un concepto, en el caso de los conceptos criteriológicos, requiere compartir los criterios de aplicación del mismo, lo que en el caso del derecho conllevaría la necesidad de convergencia con respecto a los fundamentos del derecho de los sistemas jurídicos particulares. Esto supone atribuir al positivismo tres tesis muy problemáticas: a) su análisis conceptual se basa en la identificación de los criterios de aplicación del concepto que comparten los sujetos; $b$ ) los sujetos no pueden discutir acerca de los criterios que comparten, y c) los criterios de aplicación del concepto de derecho son los criterios que emplean los juristas para determinar el valor de verdad de las proposiciones relativas a sistemas particulares. Aunque pueda resultar controvertido en sus detalles, el análisis conceptual que llevan a cabo los positivistas no se basa en la elucidación de los criterios compartidos en relación con el concepto de derecho. Si fuera así, su labor no sería muy distinta de la del análisis lingüístico. Los positivistas tratan de iluminar los aspectos centrales del fenómeno jurídico, tomando en cuenta verdades evidentes relativas al derecho y elaborando teorías que les den cabida en una suerte de equilibrio reflexivo ${ }^{58}$. Asimismo, puede defenderse que una buena explicación del concepto no tiene que comprometerse con establecer condiciones necesarias y suficientes para su aplicación, sino que supone frecuentemente destacar aspectos que no son distintivos del fenómeno, condiciones que son derrotables, y exige también ofrecer una reconstrucción adecuada de su vínculo con otros conceptos, etc. ${ }^{59}$. Además, aun asumiendo la relevancia de los criterios compartidos, resulta plausible que los sujetos discutan acerca de ellos si tomamos en consideración aspectos como el carácter opaco y no individualista de dichos criterios ${ }^{60}$. De hecho, es frecuente afirmar que un sujeto ha adquirido un concepto, a pesar de que tenga un conocimiento muy deficiente acerca de sus criterios de aplicación. Finalmente, resulta cuanto menos extraño defender que los criterios compartidos relativos al concepto son los criterios que determinan el valor de verdad de las proposiciones de sistemas jurídicos particulares. Prueba de ello es que dos sujetos de dos sistemas distintos pueden emplear distintos criterios con respecto a las proposiciones de su sistema, aunque pueda afirmarse que comparten los criterios de aplicación del concepto. Y, aunque podamos afirmar que un sujeto ha adquirido el concepto de derecho, es posible y frecuente que no conozca los criterios que determinan el valor de verdad de las proposiciones en su sistema jurídico ${ }^{61}$.

La crítica anterior no representa, por tanto, un problema para el positivista. Este no extrae sus conclusiones sobre la relevancia de la convergencia de su adopción de

\footnotetext{
57 Para una crítica detallada, vid. RAmíREz LudEÑA, 2012.

58 En este sentido, vid. SHAPIRO, 2011: 13 y ss.

59 RAZ, 2001: 6 y ss.

60 Así lo ha señalado RAZ, 2001: 14 y ss.

61 Sobre estas últimas cuestiones, vid. HimmA, 2002: 161 y ss.
} 
una determinada semántica o tipo de concepto. En esta medida, no tiene que entenderse que suscribe que el concepto de derecho es criteriológico. Pese a ello, la convergencia en los criterios que determinan el valor de verdad de las proposiciones jurídicas es central para el positivista. Así, fruto de su análisis conceptual, el positivista concluye que la convergencia entre los officials acerca de los criterios de validez jurídica es relevante, pero ello no se sigue de defender que los conceptos requieren de criterios compartidos, sino de que forma parte de la mejor explicación del fenómeno jurídico. En otras palabras, la convergencia no es relevante por el tipo de concepto que es el concepto de derecho, sino porque el resultado del análisis conceptual así lo determina.

Dicho lo anterior, conviene entonces tener presente la separación de la cuestión del concepto de derecho de la cuestión de si la existencia de criterios compartidos son relevantes. En este sentido, aunque determinados autores hayan asumido que el propio concepto de derecho opera conforme a lo que señalan las nuevas teorías de la referencia ${ }^{62}$, aquí sostendré en cambio solo su incidencia en la interpretación jurídica en un esquema positivista. Para ello, enfatizaré la relevancia de las prácticas jurídicas y de la convergencia entre los officials, también por lo que respecta a la interpretación jurídica, señalando en qué medida las teorías de la referencia pueden tener cabida.

La primera cuestión que cabe plantearse es si la convergencia es determinante para los positivistas de corte hartiano también por lo que respecta a la interpretación, o si se requiere solo acuerdo con respecto a qué fuentes son relevantes. Desde mi punto de vista, las condiciones de existencia de un sistema jurídico no pueden agotarse en la práctica de identificar textos sin una actitud crítico-reflexiva respecto de ciertos modos admisibles de otorgarles un contenido. Imaginemos que un individuo considera que el Código Civil español es parte del derecho español pero entiende que su significado debe serle atribuido a partir de un programa informático que asigna significados al azar. Imaginemos que otro individuo considera que su contenido depende de lo que su hijo de diez años dice que expresa. Finalmente, un tercer individuo entiende que aquello que expresa el Código Civil depende del lenguaje ordinario. ¿Diríamos que hay un acuerdo entre los diferentes individuos acerca de que el Código Civil es parte del derecho si no hay un acuerdo básico sobre lo que expresa el Código? Si cada uno, siguiendo su propio criterio, sostiene una interpretación radicalmente diferente de la de los demás respecto de lo que establece el Código Civil, parece que invocar el Código Civil se torna algo superfluo. Dicho en otros términos, si la actividad interpretativa no es constitutiva de la actividad jurídica, la convergencia en las fuentes podría producir los mismos resultados que su ausencia (un total desacuerdo sobre qué normas son válidas) con lo cual podría ser un hecho completamente irrelevante. Por tanto, parece que la convergencia característica de los modelos positivistas estaría desprovista de sentido si no hubiera ningún acuerdo en relación con cómo interpretar las fuentes del derecho ${ }^{63}$.

Una vez asumida la relevancia de la convergencia también para la interpretación jurídica, ¿cómo puede defenderse la incidencia de las nuevas teorías de la referencia?

62 Vid. Moore, 1994, y Coleman-Simchen, 2003. Para una crítica a sus argumentos, vid. RAmírez LuDEÑA, 2015.

${ }_{63}$ Esta idea es sugerida por PAPAYANnis (2015), y ya fue presentada en RAMíreZ LudeÑa, 2012. En RoDRÍGUEZ-PEROT (2010: 135 y ss.) se señala que entender que solo se requiere un acuerdo acerca de las fuentes haría que esta tesis fuera compatible con el iusnaturalismo. 
Es difícil cuestionar que el derecho pretende guiar la conducta y, precisamente por ello, se expresa mediante el lenguaje ordinario. Además, como hemos visto, el lenguaje ordinario frecuentemente responde a la reconstrucción ofrecida por los partidarios de las nuevas teorías de la referencia. Por ello, resulta plausible entender que el lenguaje del derecho se ajusta también, cuando incorpora esos términos del lenguaje ordinario, a dicha reconstrucción. Así, del mismo modo que ocurre en nuestras prácticas lingüísticas cotidianas, determinados términos que aparecen en los textos jurídicos manifiestan ciertos rasgos destacados por los partidarios de las nuevas teorías de la referencia. En ocasiones empleamos los términos para referirnos a los objetos pese a contar con información deficiente de ellos. Y somos capaces de hacerlo puesto que formamos parte de una cadena de comunicación, que nos remonta en última instancia a ejemplares de la clase, aunque nuestras creencias respecto a los objetos que pertenecen a la clase sean muy pobres y falibles. El uso correcto del término dependerá de cuáles son las propiedades esenciales de la clase a la que nos referimos, y la identificación de qué rasgos son determinantes puede estar en manos del hablante común o de expertos. Es lo que ocurre, por ejemplo, cuando la normativa hace referencia a la muerte, con respecto a la cual asumimos que podemos estar equivocados (y que las descripciones que asociamos con el término «muerte» pueden estar equivocadas), y tenemos deferencia con los expertos ${ }^{64}$.

Entonces, del mismo modo que ocurre con nuestras prácticas lingüísticas cotidianas, que dependen de un modo no controvertido de las creencias de los individuos, en el ámbito del derecho en algunos casos la referencia se produce en virtud de poseer determinadas descripciones, pero en otros casos no nos valemos de ellas y somos capaces de referirnos directamente a los objetos, comprometiéndonos con que caen bajo el ámbito de aplicación del término si tienen el rasgo que determina la pertenencia a la clase, aunque no conozcamos cuál es. Establecer esto último requiere de teorización. Lo anterior no debe resultar extraño: tanto la práctica lingüística como la jurídica dependen de la existencia de individuos con complejos entramados de creencias, y ello no ha obstado a su aceptación generalizada entre los filósofos del lenguaje.

A efectos de entender que son compatibles con el positivismo, es importante advertir que el hecho de que determinados casos - y no otros- queden regulados dependerá de cuál sea la práctica de identificación e interpretación de un determinado sistema jurídico. Entonces, un término quedará incorporado en un sistema jurídico particular solo contingentemente, en virtud de cuáles sean las reglas de dicho sistema, lo que viene dado por la práctica de identificación relevante. Y, dado que la consideración de las nuevas teorías de la referencia depende de cómo se usan los términos, tomarlas en cuenta respeta la convergencia que se halla en la base del esquema positivista, precisamente porque depende de que tal convergencia exista. En otras palabras, asumir una concepción como la aquí propuesta depende de la propia conducta y actitudes de los participantes, por lo que puede concluirse que el carácter convencional del derecho no tiene por qué implicar una concepción estrictamente convencional de nuestras prácticas lingüísticas. En esta medida, el derecho depende en última instancia

64 Para un análisis del caso de la muerte, pero para defender la relevancia de las aportaciones de los partidarios de las nuevas teorías de la referencia en el derecho en un esquema no positivista, vid. MoORE, 1985. 
solo de hechos sociales, que son relevantes para su identificación e interpretación, lo que conlleva que no haya una conexión identificatoria entre el derecho y la moral ${ }^{65}$. $\mathrm{La}$ incidencia de las nuevas teorías de la referencia en el derecho es entonces contingente; como hemos visto, depende de cómo se desarrolle la práctica interpretativa en una comunidad jurídica determinada ${ }^{66}$. Esto conlleva que no puede establecerse un criterio último para delimitar los supuestos de aplicación de las nuevas teorías de la referencia de aquellos otros casos en que es otra la semántica adecuada. Y que un término que en el lenguaje ordinario puede operar conforme a lo que señalan las nuevas teorías de la referencia puede operar en el ámbito jurídico según lo que señala la concepción tradicional. En definitiva, el modelo toma también en cuenta las posibles contingencias en las prácticas interpretativas de los sistemas jurídicos. Ello supone que no es necesario mostrar que hay un conjunto de términos esencialmente jurídicos que designan géneros naturales, sino solo reconocer que en algunos casos los términos de las disposiciones jurídicas operan conforme a lo que señalan los partidarios de las nuevas teorías de la referencia.

Podría, sin embargo, insistirse, en que las nuevas teorías de la referencia no son compatibles con el positivismo puesto que entonces no habría convergencia sobre las concretas exigencias de los sistemas jurídicos particulares. Sin embargo, esto no es tan extraño si tomamos en cuenta el debate que, en el seno del propio positivismo, ha tenido lugar entre positivistas incluyentes y excluyentes ${ }^{67}$. Los argumentos del positivismo incluyente pasaban por enfatizar que el derecho puede incorporar la moral, pero que en última instancia ello depende de hechos sociales. Aunque las concretas exigencias de los sistemas jurídicos puedan no ser entonces transparentes a los participantes, ello sería compatible con el positivismo al depender la reflexión moral de hechos sociales. En un sentido similar, puede entenderse que las nuevas teorías de la referencia tienen incidencia a la hora de reconstruir lo que ocurre con respecto a la interpretación de determinados términos, lo que también depende en última instancia de hechos sociales ${ }^{68}$.

¿Supone lo anterior que asumir la relevancia de las nuevas teorías de la referencia en el derecho requiere del rechazo del positivismo excluyente? Ello parecería ser el caso al requerirse, conforme a las nuevas teorías de la referencia, de teorización y considerarse que el derecho depende de cuestiones que no nos son transparentes, lo que atentaría contra la autoridad del derecho. Esta crítica sería semejante a la que se ha planteado contra el positivismo incluyente por parte de los positivistas excluyentes: si el derecho incorpora la moral, o si requiere de teorización acerca de sus exigencias, los individuos se ven obligados a llevar a cabo razonamientos y ponderaciones que el

65 Como señala BAYÓN (2002), pese a las controversias en este ámbito, el contenido mínimo del positivismo jurídico está ligado a la tesis de que la existencia y el contenido del derecho dependen de hechos sociales complejos.

${ }_{66}$ Es decir, que las nuevas teorías de la referencia merezcan atención en materia interpretativa es una cuestión en última instancia jurídica.

67 Mientras que los primeros defienden que la regla de reconocimiento puede contingentemente incorporar la moral entre las condiciones de validez jurídica, este extremo es negado por los positivistas excluyentes, quienes sostienen que la caracterización adecuada de tales supuestos requiere admitir que, para resolver estos casos, debe recurrirse a estándares extrajurídicos. Para una defensa del positivismo jurídico inclusivo, Waluchow, 1994; Coleman, 2001, y Moreso, 2001. Como principales exponentes del positivismo jurídico excluyente, vid. RAZ, 1979 y 1994 y SHAPIRO, 1998a, 1998b y 2011.

68 Vid. RAMÍREZ LuDEÑA, 2015. 
derecho pretendía excluir, lo que frustraría la pretensión de autoridad característica del derecho ${ }^{69}$.

Los casos que han centrado la discusión entre positivistas incluyentes y excluyentes son aquellos en que la moral es considerada como criterio de validez jurídica, lo que conlleva que la identificación de las normas del sistema requiere de argumentación moral. En cambio, en la versión de las nuevas teorías de la referencia que aquí se ha presentado, estamos ante supuestos en que una disposición jurídica, que forma parte del derecho en virtud de una fuente social, requiere de teorización para determinar su contenido. En este sentido, los supuestos que constituirían el paralelismo adecuado con lo que ocurre con las nuevas teorías de la referencia serían aquellos casos en que disposiciones jurídicas que son derecho en virtud de su pedigrí recurren a términos morales.

En tales grupos de supuestos, el hecho de que el derecho incorpore un determinado término moral no parece problemático, siempre que dicho término moral pertenezca al derecho por una cuestión de pedigrí y no de contenido. Ello es así porque la incorporación de un término moral en las disposiciones sí reduce el ámbito de las razones en consideración, esto es, sí supone una restricción de las opciones disponibles. En este sentido, los individuos no deben reproducir las ponderaciones que la autoridad debía llevar a cabo. De un modo similar, SHAPIRO ha señalado que, si bien la interpretación de cualquier elemento de un sistema de planes no puede ser determinado por hechos cuya existencia pretende establecer cualquier elemento de ese sistema, una regla cumpliría con su función como plan si restringe la deliberación moral ${ }^{70}$. Es decir, SHAPIRO entiende que en determinados casos en que hay apelaciones a la moral la regla puede satisfacer su función como plan en tanto excluye otras posibilidades.

69 RAZ, 1979. Aunque aquí no me referiré en ellos, los argumentos a favor del positivismo excluyente no se centran exclusivamente en la idea de autoridad. BAYÓN (2002) ha sostenido que si el derecho incorporara el razonamiento moral nos hallaríamos, o bien ante una convención que se autoanula, puesto que sería una convención para seguir criterios no convencionales, o bien sería una convención vacía. En este último caso, si, a pesar de los desacuerdos acerca de lo que prevé la convención debido a la necesidad de desarrollar la argumentación moral, seguimos hablando de la existencia de una convención que resuelve la cuestión, ello es así porque recurrimos a una convención de un alto nivel de abstracción, lo que convertiría la convención en superflua. Otros han defendido el positivismo excluyente por negar la objetividad en materia moral. En este sentido, se ha señalado que el problema del incluyente es tener que creer en la objetividad de la moral y además sostener una posición excesivamente compleja: así, si el positivismo puede dar cuenta del modo en que los argumentos morales se emplean en el razonamiento jurídico como pautas que conceden discreción, como pautas que son vinculantes pero que no son parte del derecho, o como pautas vinculantes que son parte del derecho en virtud de una fuente social, parece innecesario considerar que pueden ser pautas vinculantes que son parte del derecho por su valor moral. Por otro lado, no hay que olvidar que también podrían reconstruirse las aparentes apelaciones a la moral como referencias a la moral convencional. Finalmente, también puede rechazarse la incorporación de la moral debido a consideraciones teóricas de índole más general sobre lo que puede conocerse - por ejemplo, vinculadas con el carácter controvertido de la moral y el verificacionismo-

70 SHAPIRO, 2011: 271 y ss. y 311. El argumento fue inicialmente presentado por COLEMAN, 2001: 103 y ss. En un sentido similar, MoRESO (2001: 108 y 109) señala que las disposiciones que incorporan términos morales sí hacen una diferencia práctica puesto que su incorporación genera consecuencias en relación con diversos aspectos de la estructura institucional de un sistema. Por otro lado, es importante advertir que, a pesar de lo expresado en el texto, existen notables diferencias entre las posiciones de RAZ y SHAPIRO. Para RAZ lo que da sentido a tener derecho es que este ahorre a los ciudadanos la deliberación moral de razones preexistentes. SHAPIRO, por su parte, se centra en la lógica de los planes y lo que da sentido a tenerlos. Los planes evitan que volvamos a plantearnos las mismas cuestiones que ya hemos resuelto con la adopción del plan, reabriendo indefinidamente el balance de razones. 
Tomando en consideración lo anterior, parece entonces que la incorporación en el derecho de términos que requieren de teorización para la determinación de los casos a los que resultan de aplicación no atentaría en el sentido relevante contra la pretensión de autoridad del derecho. Precisamente porque en el modelo que he presentado resulta fundamental el modo en que está redactada la normativa a efectos de determinar qué supuestos se hallan regulados por la misma, la pretensión de autoridad práctica del derecho no se vería afectada.

Podría argumentarse que, dado que los partidarios de las nuevas teorías de la referencia entienden que lo que ocurre en muchos supuestos es que los individuos manifiestan deferencia a determinados sujetos para identificar el contenido de los términos jurídicos, ello supone una alteración fundamental con respecto a quiénes son las autoridades, y se dificulta entonces que pueda apreciarse que el derecho pretende autoridad. Sin embargo, en los supuestos en que hay deferencia a algún individuo o grupo determinado, lo que se produce no es una alteración de la autoridad práctica del derecho, sino que en realidad los individuos adoptan como autoridad teórica a un sujeto o grupo de sujetos que tratan de determinar el contenido de las disposiciones. Es cierto que, al configurarse como autoridad teórica e identificar el contenido de los términos, dichos sujetos también determinan, aunque indirectamente, sus razones para actuar. Pero ello es así precisamente porque existe una autoridad práctica que ha establecido qué disposiciones son relevantes. Por otro lado, y de acuerdo con lo señalado en el primer apartado, lo expuesto por los partidarios de las nuevas teorías de la referencia no determina que nos hallemos frente a genuinas autoridades teóricas, puesto que es posible que se cuestionen sus conclusiones y que se acabe descubriendo que también los expertos estaban equivocados.

Además, si tomamos en cuenta la posición de RAZ en el ámbito de la interpretación jurídica por lo que respecta a los términos morales ${ }^{71}$, este enfatiza que el hecho de que deba tomarse en cuenta la existencia de autoridades que manifiestan un determinado punto de vista acerca de una cuestión no conlleva que tenga que recurrirse a su intención para determinar el contenido de las disposiciones. Lo fundamental es lo que cabe entender de lo que ha quedado plasmado en la disposición. De hecho, RAZ señala específicamente que el significado depende de lo que sea razonable atribuirle a la autoridad, lo que requiere tomar en cuenta diversas consideraciones. Por tanto, tampoco este argumento permite excluir la incidencia de las nuevas teorías de la referencia.

En definitiva, la consideración de las nuevas teorías de la referencia en el derecho son compatibles con el positivismo dado que no nos conducen a asumir una relación necesaria con la moral y los hechos sociales relativos a las creencias y actitudes de los officials son determinantes. Podría, no obstante, insistirse en que ello nos lleva a una concepción metafísicamente robusta acerca del derecho, incompatible con su carácter institucional. Pero estas apreciaciones no han sido determinantes contra el positivismo incluyente y, lo que es más relevante, ya he señalado en la primera parte de este trabajo que la tesis aquí defendida es una tesis semántica (sobre cómo se usan los términos en general, y en el derecho por los operadores jurídicos), no metafísica. Entonces, en aquellos supuestos en que, en el ámbito jurídico, se enfrentan distintas concepciones 
que tratan de capturar los rasgos esenciales de una clase, o en que se deja en manos de determinados sujetos la teorización sobre la cuestión, tomar en consideración las nuevas teorías de la referencia nos permite, a diferencia de las posiciones semánticas más tradicionales con las que frecuentemente se ha vinculado al positivismo, reconstruir lo que ocurre de un modo plausible. Así, entender que ello puede hacerse de modo compatible con los postulados positivistas básicos supone poder ofrecer una respuesta para algunos de los desacuerdos a los que se refiere DWORKIN ${ }^{72}$.

\section{CONCLUSIONES}

En este trabajo he intentado mostrar la posible incidencia de las nuevas teorías de la referencia para DwORKIN y HART por lo que respecta a los desacuerdos jurídicos. Nótese que no he mostrado que DwORKIN necesite de las nuevas teorías de la referencia, sino que no son incompatibles con base en sus propios argumentos. Más allá de si es compatible con toda su teoría, o de si requiere de las nuevas teorías para dar sentido a la noción de desacuerdos teóricos, los argumentos de DwORKIN para diferenciar los conceptos interpretativos de los de clase natural no son concluyentes, por lo que las nuevas teorías de la referencia podrían resultarle de utilidad para dar cuenta de los desacuerdos sin que tenga que introducir un nuevo tipo de conceptos como los interpretativos. En el caso de HART, he tratado de mostrar que su énfasis en la relevancia de la regla de reconocimiento no obsta a que las nuevas teorías de la referencia puedan desempeñar un rol a efectos de reconstruir cómo operan determinados términos en el ámbito jurídico, de modo compatible con el carácter convencional del derecho.

Lo anterior pone de manifiesto que el punto central de desacuerdo entre ambos autores no radica en la asunción de una determinada semántica o en la defensa de un tipo particular de conceptos. Si, como he tratado de mostrar, ambas posiciones son compatibles con las tesis de los partidarios de las nuevas teorías de la referencia, parece entonces que la disputa recae en realidad en qué tipo de consideraciones son relevantes a efectos de conferir un rol a lo señalado por los partidarios de las nuevas teorías. Para DwORKIN, su relevancia depende siempre en última instancia de consideraciones de tipo normativo. Para HART, en cambio, de que las convenciones le den cabida. En definitiva, el avance en el debate entre ambas posiciones debe entonces plantearse en un nivel superior de análisis, acerca de qué consideraciones son relevantes, y no acerca de los conceptos jurídicos ni de la semántica de los términos del derecho.

\section{BIBLIOGRAFÍA}

BAYÓN, J. C., 2002: «El contenido mínimo del positivismo jurídico», en V. ZAPATERO (coord.), Horizontes de la filosofía del derecho: Homenaje a Luis García San Miguel, vol. 2, Alcalá de Henares: Publicaciones de la Universidad de Alcalá, 33-54.

72 Distinguiendo diferentes niveles de desacuerdos y enfatizando la relevancia de las nuevas teorías para reconstruir algunos de ellos, vid. RAMíREZ LUDEÑA, 2012. 
BRINK, D., 1988: «Legal Theory, Legal Interpretation and Judicial Review», Philosophy and public affairs, 17 (2): 105-148.

Coleman, J., 2001: The Practice of Principle: In Defence of a Pragmatism Approach to Legal Theory, Oxford: Oxford University Press.

Coleman, J., y Simchen, O., 2003: «Law», Legal theory, 9: 1-41.

DevitT, M., 1981: Designation, New York: Columbia University Press.

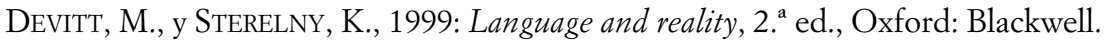

DONNELlAN, K., 1970: «Proper names and identifying descriptions», Synthese, 21: 335-358.

Dworkin, R., 1986: Law's Empire, Oxford: Hart Publishing.

- 1996: «Objectivity and Truth: You'd Better Believe it», Philosophy and Public Affairs, 25, (2): 87-139.

- 2006: Justice in Robes, Cambridge: Harvard University Press. Citado por la traducción castellana de M. IgLESIAS e I. ORTIZ DE URBINA, 2007, La justicia con toga, Barcelona: Marcial Pons.

- 2011: Justice for Hedgehogs, Cambridge: Harvard University Press.

ENDicotT, T., 2001: «Herbert Hart and the semantic sting», en J. Coleman (ed.), Hart's postscript, New York: Oxford University Press, 39-58.

Evans G., 1973: «The causal theory of names», Proceedings of the Aristotelian society, Supplementary volume, 47: 187-208.

Frege, G., 1998a: «El pensamiento», en Ensayos de semántica y filosofía de la lógica, Madrid: Tecnos. Trad. de VAldÉs VillanUeVA de «Der Gedanke. Eine logische Untersuchung», en Beiträge zur Philosophie des deutschen Idealismus, núm. I, 1918: 58-77.

- 1998b: «Sobre el sentido y la referencia», en Ensayos de semántica y filosofía de la lógica, Madrid: Tecnos. Tr. de VAldÉs VIllanUeVA de «Über Sinn und Bedeutung», en Zeitschrift für Philosophie und philosophische Kritik, 1892, C: 25-50.

GrEEN, M., 2003: «Dworkin's Fallacy, or What the Philosophy of Law Cannot Tell Us About the Law», William E Mary Law School, 1897-1952.

HarT, H., 1994: The Concept of Law, 2. ${ }^{\text {a }}$ ed., New York: Oxford University Press.

Himma, K., 2002: «Ambiguously stung: Dworkin's semantic sting reconfigured», Legal Theory, 8: $145-183$.

Iglesias, M., 1999: El problema de la discreción judicial, Madrid: Centro de Estudios Políticos y Constitucionales.

KRIPKE S., 1980: Naming and necessity, Cambridge: Harvard University Press.

LEITER, B., 2001: «Objectivity, morality and adjudication», en B. LEITER (ed.), Objectivity in law and morals, Cambridge: Cambridge University Press, 66-98.

Marmor, A., 2009: Social conventions. From language to law, Oxford: Princeton monographs in philosophy.

MARTí, G., 1995: «The Essence of Genuine Reference», Journal of Philosophical Logic, 24: 275-289.

— 2003: «The Question of Rigidity in New Theories of Reference», Nô̂s, 37: 161-179.

Moore, M., 1985: «A Natural Law Theory of Interpretation», Southern California Law Review, 58: $277-398$.

- 1987: «Metaphysics, Epistemology and Legal Theory», Southern California Law Review, 60: 453-506.

- 1994: «Law as a functional kind», en R. GEORGE (ed.), Natural Law Theories: Contemporary Essays, Oxford: Clarendon Press, 188-242.

Moreso, J. J., 1997: La indeterminación del derecho y la interpretación de la Constitución, Madrid: Centro de Estudios Políticos y Constitucionales. 
— 2001: «In Defense of Inclusive Legal Positivism», en P. CHIASsoni (ed.), The Legal Ought, Torino: Giappichelli, 37-63. Citado por la traducción en P. NAVARRO y C. REDONDO (comps.), 2002, La relevancia del derecho, Barcelona: Gedisa.

PAPAYANNIS, D., 2015: «El aspecto interpretativo de la regla de reconocimiento». Manuscrito inédito.

Pérez Otero, M., 2006: Esbozo de la filosofía de Kripke, Barcelona: Montesinos.

Putnam, H., 1975: Mind, Language and Reality: Philosophical Papers, vol. 2, Cambridge: Cambridge University Press.

RAmírez LudeÑA, L., 2012: «Los desacuerdos en el derecho», Doxa, 35: 135-155.

- 2014a: «La causalidad en las nuevas teorías de la referencia y las nuevas teorías de la referencia en la causalidad», en D. PAPAYANNIS (ed.), Causalidad y atribución de responsabilidad, Barcelona: Marcial Pons, 319-342.

- 2014b: «La teoría causal de la referencia directa y el positivismo jurídico», Diritto e Questioni Pubbliche, 947-992.

- 2015: Diferencias y deferencia, Barcelona: Marcial Pons, en prensa.

RAZ, J., 1979: The authority of law, Oxford: Clarendon Press.

- 1994: Ethics in the public domain, Oxford: Clarendon Press.

- 2001: «Two views of the nature of the theory of law: a partial comparison», en J. COLEMAN, (ed.), Hart's postscript, New York: Oxford University Press, 1-37.

RodrígueZ-Blanco, V., 2001: «"Genuine” Disagreements: A Realist Reinterpretation of Dworkin», Oxford Journal of Legal Studies, 21 (4): 649-71.

Rodríguez, J. L., y PEROT, P. M., 2010: «Desacuerdos acerca del derecho», Isonomía, 32: 119-147.

Russell, B., 1905: «On denoting», Mind, 14: 479-493.

- 1910-1911: «Knowledge by acquaintance and knowledge by description», Proceedings of the Aristotelian Society, 11: 108-128.

SEARLE, J., 1958: «Proper names», Mind, 67: 166-73.

SHAPIRO, S., 1998a: «On Hart's Way Out», Legal Theory, 4: 469-508.

- 1998b: «The Difference That Rules Make», en B. BIX (ed.), Analyzing Law. New Essays in Legal Theory, Oxford: Clarendon Press, 33-64.

- 2011: Legality, Cambridge: Harvard University Press.

Stavropoulos, N., 1996: Objectivity in law, Oxford: Clarendon Press.

Vilajosana, J. M., 2010: El derecho en acción. La dimensión social de las normas jurídicas, Barcelona: Marcial Pons.

Waluchow, W., 1994: Inclusive legal positivism, Oxford: Clarendon Press. 